\title{
Birth weight and body mass index in childhood, adolescence, and adulthood as predictors of blood pressure at age 36
}

\author{
F J Holland, O Stark, A E Ades, C S Peckham
}

\begin{abstract}
Study objective-The purpose of this study was to investigate the relation between blood pressure at age 36 , and birth weight and body mass index (BMI) in childhood, adolescence and adulthood.

Design-Prospective longitudinal survey over a period of 36 years in England, Scotland, and Wales.

Participants-A nationally representative sample consisting of 3332 men and women born in one week in March 1946. Altogether $82 \%$ of these subjects had complete data for the present analysis.

Main results-There was an inverse linear relation between birth weight and blood pressure at age 36. The relation between BMI and blood pressure at age 36 was initially inverse and became increasingly positive throughout life. Weight gain in childhood was positively associated with adult blood pressure, although less important than weight change in later life. The associations between blood pressure and birth weight, and blood pressure and adult $B M I$ were independent, and together they accounted for no more than $4 \%$ of the variation in adult blood pressure. Both low birth weight (birth weight $\leqslant 2 \cdot 5 \mathrm{~kg}$ ) and high BMI at age $36\left(B M I>30 \mathrm{~kg} / \mathrm{m}^{2}\right)$ were associated with hypertension $(>140 / 90 \mathrm{mmHg})$, but the per cent population risk of hypertension attributable to low birth weight was less than $5 \%$, and to high BMI less than $12 \%$.

Conclusions-Low birth weight and high $B M I$ at age 36 were independently related to high blood pressure. A reduction in the percentage of low birthweight babies born in the fourth decade of this century would only have a negligible effect on the incidence of adult hypertension $30-40$ years later.
\end{abstract}

7 Epidemiol Community Health 1993; 47: 432435

High blood pressure is a major risk factor for cardiovascular diseases ${ }^{1}{ }^{4}$ and a leading cause of morbidity and mortality among adults in industrialised countries. Increased blood pressure is associated with obesity ${ }^{5}$ but the underlying mechanisms are not understood. ${ }^{6}$ It has been suggested that obesity in childhood may be an important predisposing factor in the development of adult hypertension. ${ }^{7}$ This hypothesis is based on observations that children who are overweight have higher childhood blood pressure. ${ }^{78}$ Low birth weight has also been linked to high blood pressure in adulthood. ${ }^{\text {"12 }}$

The Medical Research Council National Survey of Health and Development (NSHD) provides a unique opportunity to study the link between weight in childhood and adult blood pressure. The survey began at birth and over a period of 36 years measurements of height and weight at various ages $^{1314}$ and blood pressure at 36 years ${ }^{9}$ have been obtained. An earlier report ${ }^{9}$ showed that birth weight, body mass index (BMI) at 36 years, social class and education, father's death from cardiovascular illness, and cigarette smoking were associated with adult blood pressure. This study investigates the association between blood pressure at 36 years and BMI in infancy, childhood, adolescence, and adulthood.

\section{Subjects and methods}

STLDY POPLI.ATION

The NSHD began as a study of the birth of all children born in one week in England, Wales, and Scotland in March 1946. ${ }^{15}$ The follow up sample comprises all legitimate, single births to wives of non-manual and agricultural workers and one in four of all other legitimate single births, a total of 5362 individuals. Contacts during childhood were made at intervals of two years or less and at longer intervals (maximum of seven years) in adult life. At age 36 years 3332 study members were successfully interviewed and measured in their homes. The adult study group is considered to be a representative sample of those of this age resident in Britain since birth. ${ }^{10}$

Heights and weights were measured by health visitors at ages 2 and 4 years and by school doctors or nurses at ages $6,7,11$, and 14 years. At 36 years, measurements of height and weight were carried out by specially trained nurses while at ages 20 and 26 these were self reported. All data were edited, as described in earlier publications. ${ }^{13} 1.4$

Systolic and diastolic blood pressures were measured by nurses at age 36 years using the Hawkesley random zero sphygmomanometer." Readings were taken twice in $99 \cdot 4 \%$ of the population visited, using correction factors to adjust for arm circumference. The second reading was used in these analyses.

\section{STATISTICAL METHODS}

Birth weight was expressed as a standard deviation score (BW-SDS). Mean SDS was calculated for 11 birth weight groups. Low birth weight $(\leqslant 2.5 \mathrm{~kg})$ infants formed one group while the remainder were stratified into 10ths of the BW-SDS distribution (these were of uncqual size because birth weight was recorded to the nearest quarter of a pound).

For each subject BMI $\left(\mathrm{kg} / \mathrm{m}^{2}\right)$ was calculated at each age and a standard deviation score (BMISDS) was computed separately for men and 
women using the LMS method ${ }^{17}$ based on a national survey in France. ${ }^{18}$ Mean BMI-SDS was obtained for the following age bands: 4,6 , and 7 (childhood), 11 and 14 (adolescence), 20 and 26 (early adulthood), and age 36 years (adulthood). This minimised the exclusion of subjects with missing data at some ages. For the four age bands mean SDS was calculated for each decile of the BMI-SDS distribution.

Mean blood pressure was calculated for each BW-SDS group, and BMI-SDS group at the later age bands. Then, for each age band, mean blood pressure was plotted against mean SDS within each decile. Blood pressure was also regressed against BW-SDS and BMI-SDS treated as continuous variables; linear and orthogonal quadratic effect estimates were recorded.

In longitudinal analyses, BW-SDS and BMISDS at age 36 were entered in a multiple regression model. The effect of body mass change was also investigated by regressing SDS change from birth to age 36 and change between adjacent age bands.

The relative risk and population attributable risk, and positive predictive value of low birth weight $(\leq 2 \cdot 5 \mathrm{~kg})$ and high BMI $\left(>30 \mathrm{~kg} / \mathrm{m}^{2}\right)$ at age 36 on high blood pressure $(>140 / 90 \mathrm{mmHg})$ at 36 years was estimated.

\section{Results}

Figures 1 and 2 show the mean systolic and diastolic blood pressures at age 36 years in relation to $\mathrm{BW}-\mathrm{SDS}$ group and BMI-SDS group between childhood and adulthood, restricted to those individuals with BW-SDS and BMI-SDS at each age band (1356 men and 1359 women). In men, low birth weight $(\leq 2.5 \mathrm{~kg})$ was associated with higher blood pressure. At age 36 years the picture was reversed with higher BMI associated with higher blood pressure. Between childhood, adolescence, and adulthood the initially inverse linear relationship became increasingly positive. In women, low birth weight was not asssociated with high blood pressure at age 36 , though overall, the same inverse relation was observed as with men. The linear relation between BMI and blood presssure at age 36 was already positive in childhood and became stronger with age. Superimposed on this was a U-shaped relationship. As can be seen from the regression coefficients for the quadratic terms, this became increasingly marked with age.

Tables I and II include only subjects with complete data at birth, age bands 4, 6, 7 and 11 , 14 , and age 36 ( 1421 men and 1409 women). Table I gives the results of regression models in which BW-SDS and BMI-SDS at 36 were used, separately or together, to predict blood pressure at age 36. The regression coefficients and their standard errors, when both variables are included were very similar to those obtained when the variables were entered separately. This shows that the associations which birth weight and BMI at 36 have with blood pressure are independent of each other. The percentage of variation explained in models with both factors ranged from $0.4 \%$ to $4 \cdot 0 \%$. There was no statistical interaction between birth weight and BMI at age 36 .

In further analyses (not shown), BMI at 36 and birth weight remained independently associated with blood pressure after controlling for each of the following: father's social class at age 4 , and at age 36, alcohol consumption, region of examination, and social class.

Table II shows that a unit change in SDS between birth and age 36 years was associated with a 1.5 (95\% confidence interval (CI) $0.9,2.1$ ) $\mathrm{mmHg}$ rise in systolic blood pressure in men and $1.3(95 \% \mathrm{CI} 0.7,1.9) \mathrm{mmHg}$ rise in women. The table also gives coefficients for a second model which includes covariates for SDS changes from
Figure 1: Mean systolic and diastolic blood pressure at age 36 in 1356 men, against mean standard birth weight and $B M I$ within 10 equal-sized SDS bands. The birth weight distribution has an additional group comprising those with birth weight $\leq 2 \cdot 5 \mathrm{~kg}$. Linear and quadratic estimated regression coefficients $(95 \%$ CI).

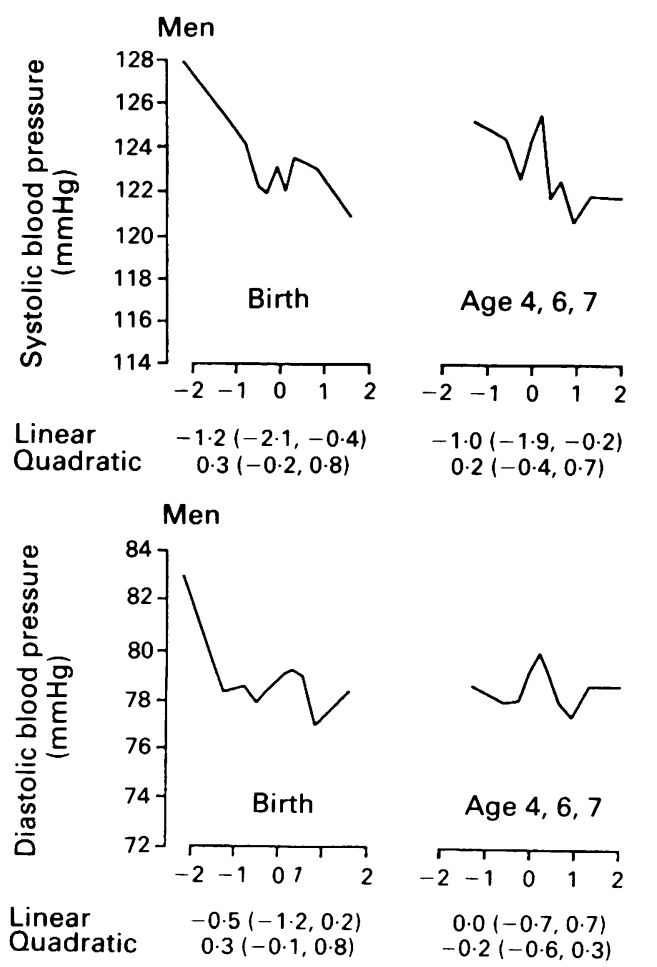

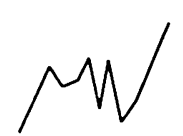

Age 11, 14

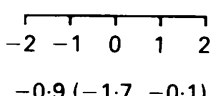

$-0.9(-1 \cdot 7,-0 \cdot 1)$

SD score

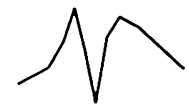

Age 11, 14

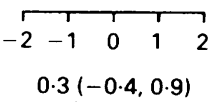

$-0.5(-0.9,-0.1)$

SD score 
Figure 2: Mean systolic and diastolic blood pressure at age 36 in 1359 women, against mean standard deviation score (SDS) for birth weight and $B M I$ within 10 equal-sized SDS bands. The birth weight distribution has an additional group comprising those with birth weight $\leq 2.5 \mathrm{~kg}$. Linear and quadratic estimated regression coefficients $(95 \%$ CI)
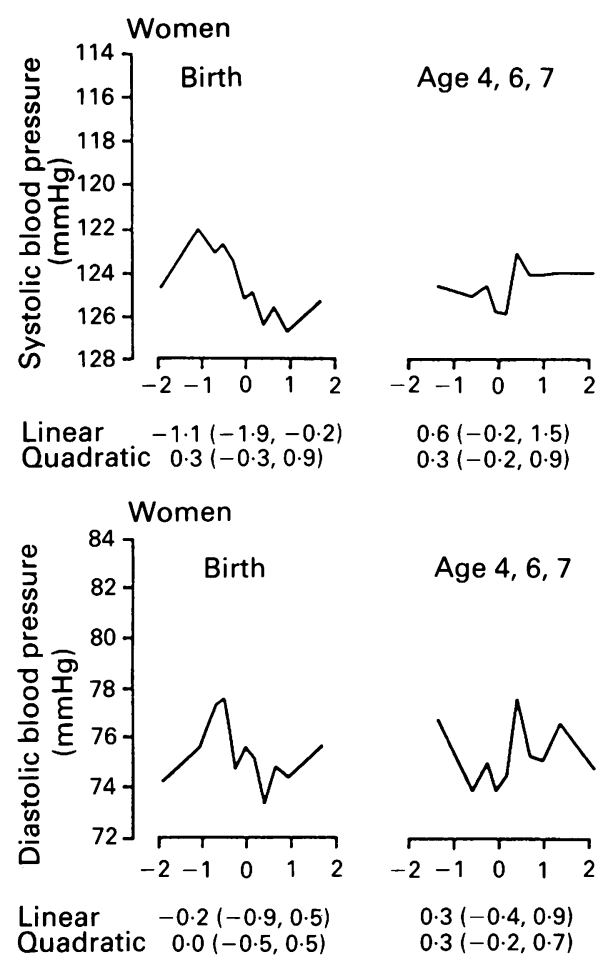

Age 4, 6, 7

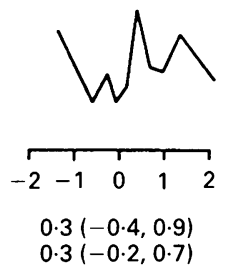

Age 20, 26

Age 36
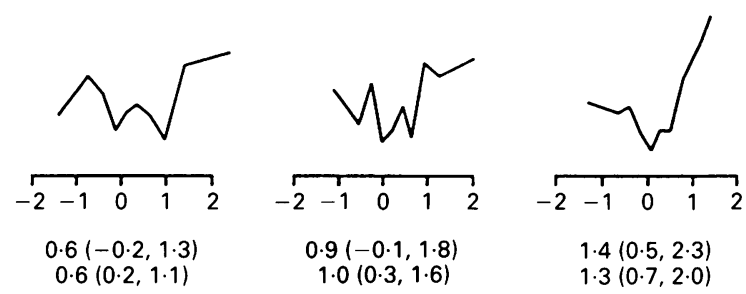

SD score

Age 20, 26

Age 36
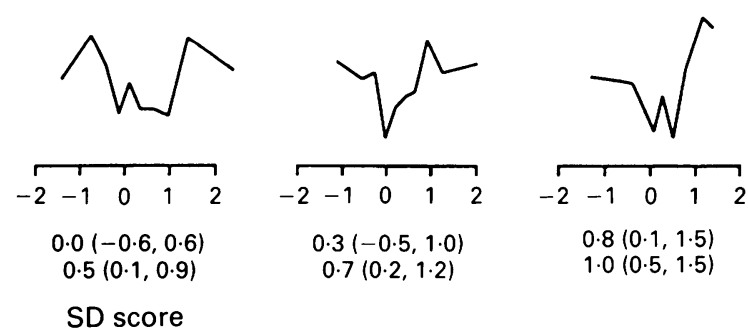

birth to childhood, childhood to adolescence, and adolescence to age 36 . In men the effect of weight change between birth and childhood was less than the effect of change between childhood and adolescence and those who gained weight in early adulthood were at more risk of increased systolic and diastolic pressure (table II). In women the relation with timing of change was much less clear, although it remained positive at all ages but weak for diastolic pressure. For both models the percentage of variation explained was small, ranging from $0 \cdot 4 \%$ to $4 \cdot 4 \%$.

Table III includes subjects with measurements at birth and age 36 ( 1611 men and 1620 women). The criterion used for low birth weight was $\leq 2.5 \mathrm{~kg}$ and $>30 \mathrm{~kg} / \mathrm{m}^{2}$ for high BMI at 36 , and $>140 / 90 \mathrm{mmHg}$ for high blood pressure. The relative risk of high blood pressure associated with low birth weight was 2.4 in men and 1.4 in women. However, low birth weight had poor predictive value for high blood pressure at age 36 -less than $9 \%$ for both sexes. Further, the percentage population risk of high blood pressure attributable to low birth weight was only $4.6 \%$ in men and $2.5 \%$ in women. High BMI at age 36 has a higher relative risk, and superior predictive value. When 13 men and 22 women with blood pressure $\leq 140 / 90 \mathrm{mmHg}$ who were being treated for hypertension at age 36 were included in the high blood pressure category, very similar though slightly lower estimates were obtained for these parameters.

\section{Discussion}

The study confirmed that low birth weight and high adult weight adjusted for height were associated with high blood pressure at age 36 years. These findings are consistent with other studies. ${ }^{59-12}$ These effects were independent of each other and are in agreement with earlier work on this cohort and another study. ${ }^{1011}$

Our study adds to previous work by examining the effect of weight in childhood, adolescence, and early adulthood and the influence of weight change between age bands on adult blood pressure. Standardisation of BMI for age allowed substantial differences in age at interview to be taken into account. A complex picture emerged: the cross sectional analyses at the different ages showed that the linear relation between weight and adult blood pressure changed from negative to positive as the child grew older. There were also marked U-shaped trends where both high and low body mass were asociated with higher adult blood pressure than was moderate BMI. This relationship, which to our knowledge has not been observed before was stronger in women. A possible explanation could be the more extreme types of body composition found in women than in men.
Table I Estimated regression coefficients (95\% confidence interval) of blood pressure at age 36 against birth weight standard deviation score (BW-SDS) and body mass index (BMI-SDS) at age 36 and percentage of variance explained

\begin{tabular}{|c|c|c|c|c|c|}
\hline & Each variable alone & & Both variables in $n$ & odel & \\
\hline & $B W-S D S$ & $\widehat{B M I}-S D \widehat{S \text { at age } 36}$ & $B W-S D S$ & & $B M I$ SDS at age 36 \\
\hline $\begin{array}{l}\text { Males }(n=1421): \\
\text { Systolic-Regression coefficient } \\
\% \text { of variance explained } \\
\text { Diastolic-Regression coefficient } \\
\% \text { of variance explained }\end{array}$ & $\begin{array}{r}-1 \cdot 1(-2 \cdot 0,-0 \cdot 3) \\
0 \cdot 5 \\
-0 \cdot 5(-1 \cdot 2,0 \cdot 2) \\
0 \cdot 1\end{array}$ & $\begin{array}{l}1 \cdot 5(0 \cdot 8,2 \cdot 2) \\
1 \cdot 1 \\
2 \cdot 3(1 \cdot 7,2 \cdot 9) \\
3 \cdot 7\end{array}$ & $\begin{array}{l}-1 \cdot 4(-2 \cdot 2,-0 \cdot 5) \\
-0 \cdot 8(-1 \cdot 5,-0 \cdot 1)\end{array}$ & $\begin{array}{l}1 \cdot 8 \\
4 \cdot 0\end{array}$ & $\begin{array}{l}1 \cdot 6(0 \cdot 9,2 \cdot 4) \\
2 \cdot 4(1 \cdot 8,3 \cdot 0)\end{array}$ \\
\hline $\begin{array}{l}\text { Females }(n=1409) \text { : } \\
\text { Systolic-Regression coefficient } \\
\quad \% \text { of variance explained } \\
\text { Diastolic-Regression coefficient } \\
\quad \% \text { of variance explained }\end{array}$ & $\begin{array}{r}-1 \cdot 1(-2 \cdot 0,-0 \cdot 3) \\
0 \cdot 5 \\
-0 \cdot 3(-1 \cdot 0,0 \cdot 4) \\
0 \cdot 1\end{array}$ & $\begin{array}{l}1 \cdot 3(0 \cdot 5,2 \cdot 2) \\
0 \cdot 6 \\
0 \cdot 8(0 \cdot 1,1 \cdot 5) \\
0 \cdot 3\end{array}$ & $\begin{array}{l}-1 \cdot 2(-2 \cdot 1,-0 \cdot 4) \\
-0 \cdot 4(-1 \cdot 0,0 \cdot 3)\end{array}$ & $\begin{array}{l}1 \cdot 2 \\
0 \cdot 4\end{array}$ & $\begin{array}{l}1 \cdot 4(0 \cdot 6,2 \cdot 3) \\
0 \cdot 8(0 \cdot 1,1 \cdot 5)\end{array}$ \\
\hline
\end{tabular}


Table II Estimated regression coefficients $(95 \%$ confidence interval) of blood pressure at age 36 against overall standard deviation score (SDS) weight change between birth and age 36 years, and against change between adjacent age bands

\begin{tabular}{|c|c|c|}
\hline Period & $\begin{array}{l}\text { Systolic } \\
\text { slope }\end{array}$ & $\begin{array}{l}\text { Diastolic } \\
\text { slope }\end{array}$ \\
\hline $\begin{array}{l}\text { Males }(n=1421): \\
\text { Birth->age } 36 \text { years } \\
\% \text { of variance explained }\end{array}$ & $\begin{array}{l}1 \cdot 5(0 \cdot 9,2 \cdot 1) \\
1 \cdot 8\end{array}$ & $\begin{array}{l}1 \cdot 7(1 \cdot 2,2 \cdot 2) \\
3 \cdot 2\end{array}$ \\
\hline $\begin{array}{l}\text { Birth->childhood } \\
\text { Childhood->adolescence } \\
\text { Adolescence->age } 36 \text { years } \\
\% \text { of variance explained }\end{array}$ & $\begin{array}{l}0 \cdot 7(0,1 \cdot 4) \\
1 \cdot 4(0 \cdot 5,2 \cdot 3) \\
2 \cdot 8(1 \cdot 9,3 \cdot 6) \\
3 \cdot 1\end{array}$ & $\begin{array}{l}1 \cdot 0(0 \cdot 4,1 \cdot 6) \\
1 \cdot 7(0 \cdot 9,2 \cdot 4) \\
2 \cdot 7(2 \cdot 1,3 \cdot 4) \\
4 \cdot 4\end{array}$ \\
\hline $\begin{array}{l}\text { Females }(n=1409): \\
\text { Birth->age } 36 \text { years } \\
\% \text { of variance explained }\end{array}$ & $\begin{array}{l}1.3(0 \cdot 7,1.9) \\
1.2\end{array}$ & $\begin{array}{l}0 \cdot 6(0 \cdot 1,1 \cdot 1) \\
0 \cdot 4\end{array}$ \\
\hline $\begin{array}{l}\text { Birth->childhood } \\
\text { Childhood->adolescence } \\
\text { Adolescence->age } 36 \text { years } \\
\% \text { of variance explained }\end{array}$ & $\begin{array}{l}1 \cdot 4(0 \cdot 7,2 \cdot 1) \\
1 \cdot 0(0,2 \cdot 0) \\
1 \cdot 4(0 \cdot 4,2 \cdot 4) \\
1 \cdot 2\end{array}$ & $\begin{array}{l}0 \cdot 5(0,1 \cdot 1) \\
0 \cdot 3(-0 \cdot 5,1 \cdot 1) \\
1 \cdot 0(0 \cdot 2,1 \cdot 7) \\
0 \cdot 5\end{array}$ \\
\hline
\end{tabular}

Our results support the hypothesis suggested by the Muscatine study that weight gain in early childhood increases the risk of high adult blood pressure ${ }^{19}$ particularly in men. We found that those who gained weight in early adult life were at greater risk of high adult blood pressure.

As the associations of low birth weight and high adult BMI with high blood pressure were independent, it follows that a gain in relative weight between these two periods will also be associated with high adult blood pressure. From data such as these, of the three candidate factors examined (low birth weight, high adult BMI, and weight change) it is not possible to determine which two are the salient determinants of adult blood pressure.

More variance in blood pressure was explained by BMI for men, particularly diastolic blood pressure. Among women the systolic blood pressure was better explained by BMI. Previous research comparing systolic and diastolic blood pressure as a predictor of subsequent mortality or morbidity have not provided consistent results. ${ }^{2} 320$

Risk of high adult blood pressure was greater for overweight adults than low birth weight infants. The percentage population risk of high blood pressure ( $>140 / 90 \mathrm{mmHg}$ ) at age 36 attributable to birth weight under $2 \cdot 5 \mathrm{~kg}$ was less than $5.0 \%$, and for BMI over $30 \mathrm{~kg} / \mathrm{m}^{2}$ at age 36 less than $12 \%$. Alternatively, one can consider the effect on adult blood pressure of a shift in the entire birth weight distribution. For example, based on the present data, a $900 \mathrm{~g}$ increase in mean birth weight would be required to increase mean systolic blood pressure by $2 \mathrm{mmHg}$ in 36 year old men. Based on data from five longitudinal studies, Stamler et al showed that this rise in blood pressure was associated with only a $3 \%$ fall in all-cause mortality. ${ }^{21}$

The 1946 birth cohort is a unique study group with subjects born during the postwar food rationing period which continued for eight years. Results obtained from this cohort may not be

Table III High blood pressure at age 36 in relation to low birth weight and high body mass index (BMI) at 36

\begin{tabular}{|c|c|c|c|c|c|c|}
\hline & & \multicolumn{2}{|c|}{$\begin{array}{l}\text { Blood pressure at } \\
\text { age } 36(\mathrm{mmHg}) \\
>140 / 90 \quad \leq 140 / 90\end{array}$} & $\begin{array}{l}\text { Relative } \\
\text { risk }\end{array}$ & $\begin{array}{l}\text { Positive } \\
\text { predictive } \\
\text { value (\%) }\end{array}$ & $\begin{array}{l}\text { Population } \\
\text { attributable } \\
\text { risk (\%) }\end{array}$ \\
\hline $\begin{array}{l}\text { Males }(n=1611) \text { : } \\
\text { Birth weight }(\mathrm{kg})\end{array}$ & $\begin{array}{l}\leq 2.5 \\
>2.5\end{array}$ & $\begin{array}{r}10 \\
119\end{array}$ & $\begin{array}{r}44 \\
1438\end{array}$ & $2 \cdot 4$ & $7 \cdot 8$ & $4 \cdot 6$ \\
\hline BMI at age $36\left(\mathrm{~kg} / \mathrm{m}^{2}\right)$ & $\begin{array}{l}>30 \\
\leq 30\end{array}$ & $\begin{array}{r}19 \\
110\end{array}$ & $\begin{array}{r}81 \\
1401\end{array}$ & $2 \cdot 6$ & $14 \cdot 7$ & $9 \cdot 1$ \\
\hline $\begin{array}{l}\text { Females }(n=1620) \text { : } \\
\text { Birth weight }(\mathrm{kg})\end{array}$ & $\begin{array}{l}\leq 2 \cdot 5 \\
>2.5\end{array}$ & $\begin{array}{r}5 \\
57\end{array}$ & $\begin{array}{r}88 \\
1470\end{array}$ & $1 \cdot 4$ & $8 \cdot 1$ & 2.5 \\
\hline BMI at age $36\left(\mathrm{~kg} / \mathrm{m}^{2}\right)$ & $\begin{array}{l}>30 \\
\leq 30\end{array}$ & $\begin{array}{l}11 \\
51\end{array}$ & $\begin{array}{r}100 \\
1458\end{array}$ & $2 \cdot 9$ & $17 \cdot 7$ & $11 \cdot 7$ \\
\hline
\end{tabular}

wholly applicable to later populations. Since then there has been a marked increase in survival of low birth weight babies and a secular trend in higher birth weight, ${ }^{22}$ and overweight and obese adults, ${ }^{23}$ which could modify the relationship between weight and blood pressure. Improvements in other factors not examined here such as general standard of living, changes in eating habits and physical activity have also changed during the last 45 years.

As there are many health risks associated with overweight and obesity attempts to reduce the prevalence, especially at young ages, need to be encouraged. In agreement with a recent report, ${ }^{24}$ we conclude that weight control programmes in adolescence and adulthood have an important role in preventing adult hypertension.

We thank Dr M E J Wadsworth and Dr C Power for their comments.

1 Rose G. Incubation period of coronary heart disease. $B M \mathcal{F}$ 1982; 284: 1600-1.

2 Tverdal A. Systolic and diastolic pressures as predictors of coronary heart disease in middle aged Norwegian men. BMF 1987; 294: 671-3.

3 Lichtenstein MJ, Shipley MJ, Rose G. Systolic and diastolic blood presssures as predictors of coronary heart diseas mortality in the Whitehall study. BMF 1985; $291: 243-5$.

4 MacMahon S, Peto R, Cutler J, et al. Blood pressure, stroke and coronary heart disease: part I, prolonged differences in blood pressure: prospective observational studies corrected for the regression dilution bias. Lancet 1990; 335: 765-74.

5 Berchtold P, Jorgens V, Finke C, Berger M. Epidemiology of obesity and hypertension. Int $\mathcal{F}$ Obes $1981 ; 5$ suppl 1:1-7.

6 Sims EAH. Mechanisms of hypertension in the syndromes of obesity. Int $\mathcal{F}$ Obes 1981 ; 5 suppl 1: 9-18.

7 Dustan HP Obesity and hypertension. In: Lauer RM Dustan HP. Obesity and hypertension. In: Lauer RM, hypertension. New York: Raven Press, 1980: 305-312.

$8 \mathrm{Dahl} \mathrm{M}$, Uhari M, Viikari J, et al. Atherosclerosis precursors in Finnish children and adolescents. III Blood pressure. Acta Paediatr Scand 1985; 318 suppl: 89-102.

9 Wadsworth MEJ, Cripps HA, Midwinter RE, Colley JRT. Blood pressure in a national birth cohort at the age of 36 related to social and familial factors, smoking, and body mass. $B M F$ 1985; 291: 1534-8.

10 Barker DJP, Osmond C, Golding J, Kuh D, Wadsworth MEJ. Growth in utero, blood pressure in childhood and adult life, and mortality from cardiovascular disease. $B M \mathcal{F}$

11 Barker DJP, Bull AR, Osmond C, Simmonds SJ. Fetal and placental size and risk of hypertension in adult life. $B M \mathcal{J}$ 1990; 301: 259-62.

12 Gennser G, Rymark P, Isberg PE. Low birth weight and risk of high blood pressure in adulthood. $B M \mathcal{F} 1988 ; 296$ : 1498-1500.

13 Stark O, Atkins E, Wolff OH, Douglas JWB. Longitudinal study of obseity in the National Survey of Health and Development. BMF 1981; 283: 13-7.

14 Braddon FEM, Rodgers B, Wadsworth MEJ, Davies JMC Onset of obesity in a 36 year birth cohort study. BMF 1986 ; 293: 299-303.

15 Wadsworth MEJ. The imprint of time: childhood, history and adult life. Oxford: Clarendon Press, 1991.

16 Wadsworth MEJ, Mann SL, Rodgers B, Kuh DJL, Hilder WS, Yusef EJ. Loss and representativeness in a 43 year follow up of a national birth cohort. $\mathcal{F}$ Epidemiol Community Health 1992; 46: 300-4.

17 Cole TJ. The LMS method for constructing normalized growth standards. Eur $\mathcal{F}$ of Clinical Nutrition 1990; 44 growth 60 .

18 Rolland-Cachera MF, Cole TJ, Sempé M, Tichet J, Rossignol C, Charraud A. Body mass index variations: centiles from birth to age 87 years. Eur $\mathcal{f}$ of Clin Nutrition 1991; 45: 13-21.

19 Lauer RM, Clarke WR. Childhood risk factors for high adult blood pressure: the Muscatine Study. Paediatrics $1989 ; 84$ 633-41.

20 Fisher CM. The ascendancy of diastolic blood pressure over systolic. Lancet 1985; ii: 1349-50.

21 Stamler J, Rose G, Stamler R, Elliott P, Dyer A, Marmot M INTERSALT Study findings: Public health and medical care implications. Hypertension 1989; 14: 570-77.

22 Alberman E, Botting B. Trends in prevalence and survival of very low birthweight infants, England and Wales: 1983-7. Arch Dis Child 1991; 66: 1304-8.

23 Gregory J, Foster $\mathrm{K}$, Tyler $\mathrm{H}$, Wiseman M. The dietary and nutritional survey of British adults. London: HMSO, 1990. 24 Seidman DS, Laor A, Gale R, Stevenson DK, Mashiach S, Danon YL. Birth weight, current body weight, and blood Danon YL. Birth weight, current body weight, and blood
pressure in late adolescence. $B M \mathcal{F} 1991 ; 302: 1235-37$. 